\title{
Putting Reasons in their Place
}

\author{
JOSÉ ÁNGEL GASCÓN
}

\author{
Department of Philosophy \\ Universidad Católica del Maule \\ Talca, Chile \\ jgascon@ucm.cl
}

\begin{abstract}
Hilary Kornblith has criticised reasons-based approaches to epistemic justification on the basis of psychological research that shows that reflection is unreliable. Human beings, it seems, are not very good at identifying our own cognitive processes and the causes of our beliefs. In this article, I defend a conception of reasons that takes those empirical findings into account and can avoid Kornblith's objections. Reasons, according to this account, are not to be identified with the causes of our beliefs and are useful first and foremost in argumentation instead of reflection.
\end{abstract}

Résumé: Hilary Kornblith a critiqué les approches raisonnées de la justification épistémique en se basant sur des recherches psychologiques qui montrent que la réflexion n'est pas fiable. Les êtres humains, semble-t-il, ne sont pas très bons pour identifier leurs propres processus cognitifs et les causes de leurs croyances. Dans cet article, je défends une conception des raisons qui prend en compte ces résultats empiriques et peut éviter les objections de Kornblith. Les raisons, selon ce récit, ne doivent pas être identifiées avec les causes de nos croyances et sont utiles avant tout dans l'argumentation plutôt que dans la réflexion.

Keywords: argumentation, epistemology, explanation, justification, Kornblith, psychology, reflection, reliabilism

\section{Introduction}

In philosophy, very rarely does an idea enjoy the consensus of all thinkers. Yet, for many centuries, reasons were considered by virtually all philosophers as an essential component of knowledge. Since Plato, it was a commonplace that mere true belief does not suffice for knowledge, and that a person should have reasons of some kind if her belief is to qualify as knowledge. Whether or not the word "reasons" was used, it was commonly assumed that most beliefs needed to be supported by other beliefs. Ideas that were 
"clear and distinct," in the case of Descartes, or perceptual beliefs, in the case of empiricists, could be taken at face value, but nonfoundational beliefs could only meet the requirements for knowledge if they were backed up by good reasons.

Argumentation theorists have-obviously enough - also emphasised the important role of reasons in the justification of our beliefs. Putting forward reasons in support of an asserted belief is considered as one of the main ways - if not the main way-to justify that belief to others. Of course, counterarguments or objections may arise, and, as a result, a critical discussion may ensue, but that is just part of the process of justification. If, by the end of the discussion, the arguer has provided sufficiently adequate and strong reasons and has dealt with their opponent's counterarguments, then they can be considered justified in their belief.

However, things changed in epistemology during the second half of the 20th century. After Gettier (1963) famously presented his counterexamples to the traditional definition of knowledge as justified true belief, new epistemological approaches were proposed that did not take into account the concept of reasons. This is true particularly of externalist conceptions of epistemic justification. According to externalists, beliefs are justified by features of the world of which the epistemic agent may not even be aware. For instance, Goldman (1967) attempted to solve the problem by proposing a causal theory of (empirical) knowledge according to which (Ibid., p. 369) "S knows that $p$ if and only if the fact $p$ is causally connected in an 'appropriate' way with S's believing p." But the causal theory soon proved to be flawed. As is well known, Goldman (1976) himself pointed out a flaw in his theory of causal connection-with his famous counterexample of the barn façades - and replaced it with a reliabilist theory. According to his new proposal, "a person is said to know that $\mathrm{p}$ just in case he distinguishes or discriminates the truth of $\mathrm{p}$ from relevant alternatives" (Ibid., p. 772).

Reliabilism was to become the most successful externalist approach to knowledge. And it is clear that, in a reliabilist account of the criteria for knowledge, any idea of reasons is absent. As long as the epistemic agent is reliable, she does not need to be aware of her own reliability in order to know - and hence she does 
not need to have any reason for her belief. As Goldman himself explains, when comparing his theory to the Cartesian perspective (1976, p. 790):

My theory requires no justification for external-world propositions that derives entirely from self-warranting propositions. It requires only, in effect, that beliefs in the external world be suitably caused.

Reliabilist theories of knowledge are thus a threat to the centrality of reasons in epistemic justification. But there is a sense in which such a threat could be safely ignored: reliabilist theories have been, in large part, a reaction to Gettier's counterexamples, and those situations are arguably not representative of our usual epistemic practices. They portray bizarre circumstances that rarely, if ever, take place in real life. Moreover, reliabilist theories seem most apt for perceptual beliefs, but they either explicitly limit themselves to those or struggle to explain inferential beliefs as well - with dubious success. In the case of our everyday inferential beliefs, one could argue, a reasons-based account of knowledge is still needed.

Nevertheless, even if that conclusion is granted, the notion of reasons is still in trouble. More recently, Hilary Kornblith, who endorses a reliabilist theory, has put forward some profound objections to the centrality of reasons in epistemology which are not based on weird Gettier-like scenarios. Kornblith's criticisms are highly accurate and are relevant to all our everyday practices of attribution of knowledge. As such, I believe they must be addressed by whoever supports the importance of reasons in epistemology - as is my case. This is the purpose of the present paper. At the same time, my discussion will reveal certain features of reasons that, it seems to me, we must take into account in order to have an acceptable, realistic conception of reasons.

In the following section, I will present the core of Kornblith's objections to the concept of reasons, stressing those aspects in which I believe he is right. Then, in sections three and four, I will outline a picture of reasons that can be saved from those criti- 
cisms, and I will defend it as the most plausible one for epistemology and argumentation theory.

\section{Kornblith's objections}

In On Reflection, Kornblith criticises the idea that reflective scrutiny of our beliefs and our reasons is essential to knowledge. His objections are both theoretical and empirical, but I will focus on the latter, for I am mainly interested in the challenge that current empirical research creates for argumentation and reasons-based epistemology - a challenge that Kornblith insightfully grasped. Since I will leave his theoretical considerations aside, I admit from the beginning that, in this article, I will not conclusively establish the importance of reasons for epistemic justification. Nevertheless, I will address what I take to be Kornblith's most powerful objections, and this will help me outline an empirically-informed conception of reasons. This, I believe, will be the conception of reasons that argumentation theory and epistemology should adopt if we are to take seriously the findings of psychological research.

It is widely assumed, both within and outside of philosophy, that an unreflective belief is not as reliable and valuable as a belief upon which one has reflected. According to this idea, knowledge requires a certain degree of reflection on the grounds and the merits of our beliefs. We can find this view, for example, in Ernest Sosa's epistemology — one of the targets of Kornblith's criticisms. In his virtue epistemology, Sosa considers two kinds of knowledge: animal knowledge and reflective knowledge. The characterisations of both kinds of knowledge have varied slightly throughout the author's intellectual development, ${ }^{1}$ but in general, in order to have animal knowledge, it is enough to have a true belief reliably produced, whereas reflective knowledge also requires the agent's awareness of her own reliability. Thus, Sosa acknowledges the merits both of reliabilism—-by admitting animal knowledge - and of a reasons-based epistemology — in his reflective knowledge. Yet, the two kinds of knowledge are not equal. He claims that a reliable response supplemented by a reflective under-

\footnotetext{
1 The details are not relevant here. The initial proposal can be seen in Sosa (1991) and a more recent proposal in Sosa (2007).
} 
standing "would in general have a better chance of being right" and therefore "reflective knowledge is better justified than corresponding animal knowledge" (1991, p. 240). Reflective knowledge, according to Sosa, provides "a more comprehensive grasp of the truth than we would have in its absence" (1997, p. 421), it is "a better knowledge" (Ibid., p. 422), and it does not consist merely in tracking the world but also requires "awareness of how one knows, in a way that precludes the unreliability of one's faculties" (Ibid., p. 427).

Kornblith (2012) admits that this is an attractive idea-one that even seems to be common sense. However, he asks a crucial question that most philosophers, having assumed that we all ought to reflect on our beliefs, failed to ask: are reflective beliefs really more reliable than unreflective beliefs? As he puts it (Ibid., p. 17):

Just as first-order beliefs which have gone unscrutinized may be reliably produced or, alternatively, the product of unreliable processes, the processes by which we reflectively check on first-order beliefs may themselves be reliable or instead, quite unreliable. The mere fact that we have applied some additional check on our first-order beliefs tells us nothing about the reliability of the checking procedure.

This is not a merely theoretical issue. Philosophers have too often taken for granted that reflection is a reliable mechanism to detect our mistakes and improve the quality of our beliefs; but, as it turns out, the empirical research undermines that claim. If the purpose of reflection is to identify the process by which a belief was formed and to check its reliability, then it seems pretty clear that reflective scrutiny of our beliefs is mostly unhelpful. Indeed, Kornblith points out that a great deal of experiments have shown that we lack reflective awareness of the formation of our beliefs (Ibid., p. 23): "Subjects are often ignorant of the actual source of their beliefs, and reflection is, in many cases, incapable of revealing it to them."

In a previous work on a reliabilist approach to knowledge, Knowledge and its place in nature, Kornblith had already elaborated on this objection. In chapter four of that book, he reviewed several psychological studies that show the existence of cognitive 
biases in our everyday reasoning. Those studies cast doubt on the epistemic value of solitary reflection not only because our reasoning may be biased, but also, and mainly, because we are not even aware of those biases. The scrutiny of our beliefs through introspection does not help us detect biases because it "simply does not provide us with accurate information about the etiology of our mental states" (2002, p. 114). The process by which we acquire our beliefs is, as many studies have shown, in large part unconscious. Consequently, Kornblith warned us (Ibid., p. 115):

In cases such as these, introspection is not only powerless to detect the errors that we make, but in misdiagnosing the source of our judgments and our reasons for believing, the reliance on introspection as a tool for self-evaluation merely instills a false sense of confidence in an already misguided agent.

And he insisted that "A tendency to rely on introspection in pursuing the project of epistemic self-improvement will most likely lull the agent into a false sense of security" (Ibid., p. 116).

The claim that human beings lack introspective access to the mental processes of formation and modification of beliefs was actually not new when Kornblith published his essays. It was defended several decades ago by Nisbett and Wilson (1977), and it is today a widely accepted finding in cognitive psychology (cf. Kunda 1999). Nisbett and Wilson reviewed a substantial number of experiments in which the participants had changed their minds due to a certain stimulus but afterwards were not capable of correctly identifying the cause of their behaviour in their verbal reports. Furthermore, the two psychologists conducted specific experiments that showed that the participants did not know the real motivations behind some of their decisions. In one of those studies (Nisbett and Wilson 1977, p. 243), they asked the participants to evaluate four pairs of stockings and to choose the pair of the best quality. There was a trick: the four pairs were identical. Most participants showed a position effect, choosing the right-most pair in the array. However, when they were asked to provide reasons for their choice, none of them mentioned the position of the stockings as a reason. In fact, when expressly asked whether the position had influenced their decision, virtually all of them denied it. 
In another experiment (Ibid., p. 244), the participants were shown an interview with a teacher who spoke English with a European accent. Two videos were recorded. In one of them, the teacher answered the questions in a pleasant and enthusiastic way; in the other, the teacher was rigid and intolerant. Half the participants saw the first video and the other half saw the second one. Then, they were asked to rate the teacher's likability and also three of his attributes, his physical appearance, his mannerisms, and his accent, which were, obviously, the same in both videos. The results showed that most of the participants who saw the first video found those attributes of the teacher attractive, while most of the participants who saw the second video rated those attributes as irritating. That is, the teacher's behaviour affected their ratings of the invariable attributes. However, when the participants were asked about their reasons for those ratings, they all denied that influence, and some of them even claimed that the influence worked the other way around: they did not like the teacher because of their negative ratings of those attributes.

Empirical studies such as these do not simply show that introspection is fallible and, in fact, fails in certain cases - such a conclusion would not be a big problem for advocates of reflection. On the contrary, the results of the last fifty years of research on human reasoning convincingly prove that introspection and reflection are indeed very unreliable, rather than failing only in certain, special settings. Nisbett and Wilson designed their experiments with the deliberate purpose of testing cognitive processes "of a routine sort that occur frequently in daily life" (Ibid., p. 242). The problem, then, is widespread. ${ }^{2}$

\footnotetext{
${ }^{2}$ It might be thought that there is a simple answer to this problem: in light of the current replication crisis in psychology, those empirical findings cannot be trusted. While that would certainly be a relief for those (like me) who still have faith in human reason, I do not think that the findings can be so easily dismissed. Here I have focused on Nisbett and Wilson's experiments, but subsequent research has reinforced the view that human beings lack introspective access to the causes of our actions (see Carruthers 2011; Wegner 2002; Wilson 2002). To my knowledge, the results of that research have not been affected by the replication crisis (so far). In particular, Carruther's theory, which denies that there is such a thing as introspective access to our judgements and decisions, still seems to be supported by reliable evidence (Rimkevičius 2020). So, unless
} 
The psychologist Emily Pronin (2007) has coined the term "bias blind spot" to refer to the fact, sufficiently confirmed nowadays, that we are incapable of perceiving our own biases, whereas at the same time we are prone to exaggerate the presence of biases in others. As she explains (Ibid., p. 38), one of the causes of the existence of the bias blind spot is that, even though many of our judgements and our acts are caused by unconscious processes, we tend to rely on introspection in order to examine our reasoning. Given that our biases are produced by unconscious mechanisms, introspection is very unlikely to detect them, and it generates the misleading impression that we are "objective" (Ibid., p. 40). So, as Kornblith argues, reflection does not eliminate biases and creates a mistaken feeling of confidence.

Thus, Kornblith's conclusion is categorical and devastating to theories of epistemic justification that rely on reflection (2002, p. 122):

The kind of reflection that typically goes on in real human agents is thus not the sort of thing that we would want to encourage. It does not improve one's epistemic situation; it does not typically aid in the project of getting an accurate understanding of the world; in cases where epistemic improvement is needed, it typically results in a more confident, but no less misguided, epistemic agent. It would clearly be unreasonable to suggest that this sort of process is an essential ingredient in knowledge.

On the basis of that empirically-informed criticism of reflectionas well as some theoretical considerations that I have not addressed here-Kornblith (2015) claims that perhaps epistemology should not take seriously the notion of reasons for belief. After all, even if reasons seem to be an essential component of how we feel the processes of belief acquisition and modification proceed, the psychological research has shown that our personal experience of those processes is not to be trusted. Should we then abandon the idea that reasons are essential in attributions of knowledge?

and until the results of all those numerous experiments are convincingly challenged, my view is that we should take them seriously. I thank a reviewer for pressing this issue. 
Even though Kornblith's objections against the role of reflection in epistemology are, in my view, insightful and accurate, I believe that the notion of reasons can be saved from his criticisms. We just have to take note of the scope of Kornblith's criticisms and adopt a conception of reasons that fits into what we know about human reasoning today. In particular, in order to move from his objections against reflection to his objections against reasons, Kornblith needs to make two assumptions: (1) reasons are the causes of our beliefs, and (2) the place of reasons is solitary reflection. In the following two sections, I will argue for a conception of reasons in which these two assumptions are rejected.

\section{Justifying and explanatory reasons}

Kornblith's objections against the notion of reasons for belief clearly assume that reasons must be what cause our beliefs. Research in cognitive psychology has shown that we are not aware of what it is exactly that causes our beliefs and that the reasons we put forward are a posteriori rationalisations. That is why, if we understand the concept of reasons as entailing that reasons must identify the causes of our beliefs and actions, we surely had better dispense with that concept altogether. But there is another possibility. Instead of conceiving of reasons as causes, we could conceive of them as epistemic grounds for our beliefs.

Here I am pointing to an important distinction that Kornblith does not take into account: reasons can be used to justify an action or to explain it. In philosophy of action, authors such as Searle (2001, p. 110) and Alvarez (2009) have distinguished between explanatory reasons, which refer to the issue of why someone did something, and justifying reasons, which make the action right in some respect ${ }^{3}$. Explanatory reasons can be causes-at least in some very vague and uncontroversial sense in which causes are what moves us to act in a certain way-but justifying reasons need not be. Undoubtedly, researchers in cognitive psychology tried to identify the explanatory reasons for our actions, and they showed that we are not very good at identifying them ourselves. But this

\footnotetext{
${ }^{3}$ Alvarez also considers a third category of reasons: motivating reasons. But this need not concern us here.
} 
does not yet tell us anything about justifying reasons and notice that these are precisely the reasons that are relevant in epistemic justification.

When, on the basis of findings in psychological studies, Kornblith draws the conclusion that reasons might not have a place in epistemic justification, it seems to me that he is conflating both kinds of reasons. His assumption that reasons must be the causes of our beliefs seems to amount to an assumption that whatever explains the acquisition of a belief must be what justifies it. But, if we reject that assumption, Kornblith's empirical objections to the notion of reasons for belief vanish.

There are, in fact, considerations that have nothing to do with avoiding Kornblith's objections and that count in favour of adopting a conception of reasons as different from causes (Evans 2013, pp. 2947-2949). To begin with, consider those cases in which evidence for a belief is found after such a belief has been formed in someone's mind. This happens very often with scientific theories. Arthur S. Eddington's observation in 1919 that light rays are bended by the gravitational field of the sun surely provided Einstein with a good reason for his theory of relativity, in spite of the fact that Einstein had already come up with that theory. According to a causal conception of reasons, the results of Eddington's experiment should not count as a reason for Einstein.

Moreover, an important aspect of the practice of giving reasons for beliefs is that reasons can, and should, be abandoned when they are found to be defective. If I hold a belief $p$ on the basis of the reason $q$, and I find out that $q$ is faulty, then I should, if I am rational, stop considering $q$ as a reason for $p$. Furthermore, I should probably, if $q$ was my only reason for $p$, give up my belief that $p$. But, in a causal conception, that does not make sense: the causes of my belief were those and I cannot simply change them at will-for I cannot change the past.

There are, therefore, several considerations that count in favour of distinguishing between explanatory and justifying reasons and against the identification of justifying reasons with causes of belief. Kornblith is aware that if we remove the assumption that reasons are causes, then his criticisms do not show that we should 
abandon the concept of reasons. But he asks us to consider the following example (2015, p. 237):

Suppose Jim is part of a faculty search committee, and he is reading over dossiers of applicants. A woman who has applied, with some undeniably strong credentials, is favored by some members of the search committee, but Jim has placed her file in the reject pile. When asked why he found her candidacy unacceptable, Jim cites a number of features of her record. These, he says, are the reasons he believes that she is an unacceptable candidate.

Suppose now that his colleagues point out to Jim that many studies in social psychology show that women candidates are rated lower than men candidates with the same credentials. This seems to imply that the reasons that are given for the ratings cannot be the actual reasons. But, if we dissociate reasons from the causes of our beliefs, as I am proposing here, then Jim could simply say that the causes of his belief are irrelevant and that he cannot be wrong about his actual reasons - they are just the reasons he put forward, by definition. Thus, Kornblith concludes that this view is "extremely implausible" (Ibid., p. 238).

In my view, that view is not as implausible as it seems at first sight. Jim may maintain that the reasons he offered for the rejection are his actual reasons if he wishes, but that says nothing about whether they are good reasons. As a matter of fact, what the evidence of gender bias does is to raise doubts about the quality of those reasons. When reasons for a belief are good, they must, among other things, indicate features of the case that are epistemically relevant in all similar cases. Gender, in this case, is not epistemically relevant, so the variation in the kinds and strength of reasons when the candidate is a woman and when the candidate is a man would reveal a problem of incoherence. Thus, the proper reaction to those studies in social psychology is not to disregard all reasons against any woman candidate - that would be absurd. The proper reaction is to moderate our trust in the quality of our reasons and double-check them, especially checking for coherence with past decisions and past reasons.

Consider a last example that may show why it could not be a good idea to identify reasons with psychological causes for beliefs. 
Personally, I do not believe in the existence of an afterlife. There may be many causes for that belief of mine. But I am pretty sure that an important part of the explanation of why I am convinced that there is no afterlife is that I grew up at the end of the 20th century and went to university at the beginning of the 21 st century in a social environment in which such religious ideas were out of fashion and even discouraged. Obviously, I have what I take to be very good reasons for my belief, and they have nothing to do with that historical explanation. However, if reasons are seen as causes, then my actual reasons would have to include those facts about my background. It is easy to see how such a view could rapidly lead to wholly ad hominem argumentation in all theoretical domains. Justifying reasons, then, should not be seen as the causes of our beliefs, and this solves the problem of which Kornblith insightfully made us aware.

\section{Reasons in argumentation}

At this point, one could ask: what are reasons worth if they do not identify the psychological causes of our beliefs? Obviously, their natural place cannot be solitary reflection and introspection with the aim of assessing the origin of what we believe. As Kornblith has convincingly argued, reflection is very unreliable as a method of scrutiny of our beliefs. Nevertheless, there is a setting in which reasons fit comfortably and to which, in general, theories of epistemic justification have paid insufficient attention: argumentation.

While reasons have traditionally been present in epistemology-as mentioned in the introduction-actual argumentation between people has been largely ignored. Either the epistemic agent had reasons, in which case they were justified, or they did not have them and therefore they were not justified; reasons were never exchanged in order to resolve the issue of justification. What happened with Gettier's counterexamples shows, in my view, to what extent reasons were conceived in solitary reflection only. Virtually all epistemologists agreed that the protagonists of Gettier's counterexamples were justified in their beliefs - even if they did not qualify as knowers. It is clear that they had what they took to be good reasons for their beliefs, but would other people accept 
those reasons? Would we accept them? We all know that those reasons were based on false beliefs, of course, so obviously Gettier's victims would not be able to convince us. But, then, why do we claim that they were justified? Does it make any sense to say that someone is justified on the basis of reasons that we would not reasonably accept?

Such questions were not asked by epistemologists simply because their framework did not provide any room for interpersonal argumentation. As Adam Leite (2004) argues, traditional epistemology has focused on the state of being justified, rather than the activity of justifying a claim. He explains (Ibid., p. 222):

According to these theories, the justificatory status of a person's belief is determined by certain facts which obtain prior to and independently of the activity of justifying. The activity itself plays no role in determining justificatory status; it is simply a secondary and optional matter of attempting to determine and report, as far as is conversationally necessary, the prior and independent facts which determine the justificatory status of one's belief.

Leite calls this view of epistemic justification the Spectatorial Conception. From this perspective, it is no wonder that epistemic justification can only be understood as a person's reflection on their beliefs - or, in externalist theories such as reliabilism, as the relation of a person's cognitive abilities to the world. According to Leite (Ibid., p. 227): "in dismissing our overt deliberative and justificatory activities, the Spectatorial Conception loses sight of the very idea of a person's holding a belief for a reason." In particular, he argues that those approaches to epistemic justification do not give an adequate account of what it is to commit oneself to reasons and to be accountable for them. Thus, he proposes an account of justification that focuses on the argumentative activity (Ibid., 239):

The basic point of the ordinary conversational activity of requesting and offering reasons in defense of beliefs is to provide a setting within which entitlements to hold beliefs can be challenged, defended, established, and shared. To develop a justification for one's belief is to attempt to establish or secure a positive norma- 
tive status by offering reasons in one's defense, and successfully justifying a belief is more like achieving a checkmate than like showing or reporting that one has won the game.

Conceiving of the link between reasons and beliefs in this way, as something that is established by means of commitments that are publicly acquired by the epistemic agent, does not rule out evaluation and criticism of reasons - as Kornblith seemed to fear. On the contrary, it allows us to understand, among other things, our obligation to revise our reasons if they are defeated. The argumentative conception of reasons can thus explain what the causal conception could not: the act of committing oneself to reasons.

It seems, then, that the natural place of reasons is not solitary reflection but interpersonal argumentation. Indeed, recent evolutionary accounts of human reason provide support for this idea. According to Mercier and Sperber (2017), the main function of human reason is not the improvement of individual cognitive abilities - for it leaves much to be desired on that score-but of argumentative abilities. Reason did not evolve in order to improve solitary reflection but as a response to problems that arise in social interactions. In particular, they hold that

Reason fulfils two main functions. One function helps solve a major problem of coordination by producing justifications. The other function helps solve a major problem of communication by producing arguments (Ibid., p. 183).

These capabilities of producing justifications and arguments developed, naturally enough, together with a capacity to evaluate the reasons that we receive from others (Ibid., p. 332). The main context of use of reasons, then, is not individual reflection but the interaction with other people. Of course, there is also solitary reasoning, but what happens when we reason on our ownaccording to Mercier and Sperber-amounts to a rehearsal of our future discussions with others.

If the argumentative theory of reasoning is correct-and the results of many studies in cognitive psychology seem to support it (Mercier 2016) - then it could explain the importance of the public act of committing oneself to reasons, which Leite emphasised. 
Mercier and Sperber (2017, p. 109) overtly admit that most of our reasons are a posteriori rationalisations - as Kornblith argued. In fact, they claim (Ibid., p. 112) that "The main role of reasons is not to motivate or guide us in reaching conclusions but to explain and justify after the fact the conclusions we have reached." However, it seems to be the case that, if human reason works as Mercier and Sperber argue that it does, then even justifying reasons might guide us in forming beliefs and making decisions. Let me attempt to explain why.

When we reason on our own, the authors claim, we often arrive at beliefs and decisions that we will be able to justify to others. We tend to choose those beliefs and decisions for which we have reasons that other people will probably accept. As Mercier and Sperber (Ibid., p. 255) explain:

This common phenomenon is known as reason-based choice: when people have weak or conflicting intuitions, reason drives them toward the decision for which it is easiest to find reasonsthe decisions that they can best justify.

Now consider what happens when a person commits themself to certain reasons. When we give reasons, we publicly acknowledge their normative force, and we commit ourselves to adapting our future behaviour to those or similar reasons. If at some point our actions or beliefs contradict our previous commitment to those reasons, we had better be able to provide another very good reason that justifies our incoherent behaviour. That means that, when we are undecided about what to do or believe, the action or belief that will be easier for us to justify will be the one which fits into the reasons to which we are committed. Putting forward reasons and committing oneself to them may, thus, influence our prospective reasoning.

On the other hand, the reasons that we never make public or that are understood as mere causes of our beliefs do not commit us to anything. If there is no public commitment, then there is no social pressure to behave in a way that is coherent with those commitments. Reasons in solitary reasoning, or reasons that 
amount to causes, do not create any normative constraint for our future decisions.

Hence, an argumentative conception of justifying reasons in epistemology that regards them as public commitments rather than causal explanations, not only can avoid Kornblith's objections but also fits better with evolutionary accounts of reason such as Mercier and Sperber's. Kornblith's criticisms should make us reconsider what we mean by "reasons," but they should not make us abandon the concept of reasons in epistemology.

\section{Conclusion}

Kornblith's criticisms against reflection in epistemology are, I believe, very relevant and accurate, and they should make us doubt the value of introspection and solitary reasoning. However, in this paper, I have argued that his empirical objections against reflection do not warrant the conclusion that reasons might have no place in epistemic justification. I have argued that the step to that conclusion requires two assumptions that can be rejected: that reasons are to be identified with the causes of our beliefs and that the place of reasons is individual reflection.

By rejecting those two claims, we take a path towards a more realistic, empirically-informed conception of reasons. Thus, the answer to Kornblith's criticisms has led us to a picture of reasons that is supported by what we know nowadays about human reasoning. Reasons in epistemology are justifying reasons; they are public commitments that provide epistemic support to our beliefs; they are not necessarily what caused our beliefs. The natural habitat of reasons is interpersonal argumentation, where they can be given, requested, and challenged; they do not fare well in solitary reasoning. Therefore, theories of epistemic justification should pay more attention to the activity of justifying a belief to other people, rather than to an alleged state of being justified.

\section{Acknowledgements}

Some of the ideas of this paper were presented at the I Congreso Iberoamericano de Argumentación, 24-27 of August 2019, in Medellín (Colombia). I am very grateful to the audience for the 
discussion that followed, especially to Cristian Santibáñez, Hubert Marraud and Paula Olmos. This research was possible thanks to the postdoctoral scholarship FONDECYT n. 3190149 of ANID/CONI-CYT, and also to the project PGC2018-095941B100 , "Prácticas argumentativas y pragmática de las razones," of the Spanish Ministerio de Ciencia, Innovación y Universidades Agencia Estatal de Investigación.

\section{References}

Alvarez, Maria. 2009. How many kinds of reasons? Philosophical Explorations 12(2): 181-193.

Carruthers, Peter. 2011. The opacity of mind: An integrative theory of self-knowledge. Oxford: Oxford University Press.

Evans, Ian. 2013. The problem of the basing relation. Synthese 190(14): 2943-2957.

Gettier, Edmund L. 1963. Is justified true belief knowledge? Analysis 23(6): 121-123.

Goldman, Alvin I. 1967. A causal theory of knowing. Journal of Philosophy 64(12): 357-372.

Goldman, Alvin I. 1976. Discrimination and perceptual knowledge. Journal of Philosophy 73(20): 771-791.

Kornblith, Hilary. 2002. Knowledge and its place in nature. New York: Oxford University Press.

Kornblith, Hilary. 2012. On reflection. Oxford: Oxford University Press.

Kornblith, Hilary. 2015. The role of reasons in epistemology. Episteme 12(2): 225-239.

Kunda, Ziva. 1999. Social cognition: Making sense of people. Cambridge, MA: MIT Press.

Leite, Adam. 2004. On justifying and being justified. Philosophical Issues 14: 219-253.

Mercier, Hugo. 2016. The argumentative theory: Predictions and empirical evidence. Trends in Cognitive Sciences 20(9): 689-700.

Mercier, Hugo and Dan Sperber. 2017. The enigma of reason. Cambridge, MA: Harvard University Press.

Nisbett, Richard E. and Timothy D. Wilson. 1977. Telling more than we can know: Verbal reports on mental processes. Psychological Review 84(3): 231-259.

Pronin, Emily. 2007. Perception and misperception of bias in human judgment. Trends in Cognitive Sciences 11(1): 37-43. 
Rimkevičius, Paulius. 2020. 'The Interpretive-Sensory Access theory of self-knowledge: Empirical adequacy and scientific fruitfulness'. Problemos 97: 150-63.

Searle, John R. 2001. Rationality in action. Cambridge, MA: MIT Press.

Sosa, Ernest. 1991. Knowledge in perspective: Selected essays in epistemology. Cambridge: Cambridge University Press.

Sosa, Ernest. 1997. Reflective knowledge in the best circles. The Journal of Philosophy 94(8): 410-430.

Sosa, Ernest. 2007. Apt belief and reflective knowledge: A virtue epistemology (Vol. 1). New York: Oxford University Press.

Wegner, Daniel. 2002. The illusion of conscious will. Cambridge, MA: MIT Press.

Wilson, Timothy D. 2002. Strangers to ourselves: Discovering the adapting unconscious. Cambridge, MA: Harvard University Press. 